\title{
Evaluation of an Afterschool Children's Healthy Eating and Exercise Program
}

\author{
Chia-Liang Dai", Laura A. Nabors, Keith A. King, Rebecca A. Vidourek, Ching-Chen Chen, \\ Nhung Hoang and Katherine G. Mastro
}

College of Education, Criminal Justice and Human Services, University of Cincinnati, P.O. Box 210002, 410 TC, Cincinnati, OH 45221, USA

\begin{abstract}
Background: The purpose of this study was to examine the feasibility of the Children's Healthy Eating and Exercise Program (CHEE) in an afterschool program of an elementary school.

Methods: Students in a low-income elementary school were recruited to participate in the program. Thirty-three children were in the intervention group. Twenty-four children in the comparison group were recruited from after school clubs in the same elementary school. The CHEE Program consisted of 18 sessions, featuring nutrition (20 min) and physical activity (40 $\mathrm{min}$ ) lessons. Nutrition lessons were adapted from the Traffic Light Diet. Other lessons included MyPlate, my refrigerator, my lunchbox, and a healthy foods tasting activity. Multiple physical activities were utilized in the program including soccer, dance, relay races, tag, and other fun games. Data were collected at the beginning and end of the program.

Results: Children in both groups reported eating more vegetables at the post-intervention measurement. Children in the intervention group indicated that they learned about healthy eating and new physical activities due to their participation in the program.

Conclusions: Future studies are needed to discover barriers to behavior change as well as apply a more rigorous design to examine the impact of the CHEE Program.
\end{abstract}

Keywords: Afterschool health education program, low-income children, healthy eating, nutrition education, physical activity.

\section{INTRODUCTION}

Childhood obesity is a nationwide problem and is steadily affecting children's health in the United States (U.S.). Approximately, $18 \%$ of children are obese, and more than one third of children and adolescents are overweight or obese in the U.S. [1]. The consequences of obesity are among the most serious public health challenges. Overweight and obese children and adolescents suffer from both short-term and long-term health consequences [2]. Overweight and obesity is responsible for physical effects such as diabetes and mental health issues such as low self-esteem [3]. Children often struggle with low self-esteem which is attributed to a lack of peer acceptance [4]. Overweight and obesity, as well as the associated negative health consequences, are largely preventable [5]. Several studies have been done to investigate predictors of childhood overweight or obesity [6-8]. Findings indicated that at least three behaviors are modifiable and particularly important for children, which are engaging in regular physical activity, consuming more fruits and vegetables, and eating less "junk food."

*Address correspondence to this author at the College of Education, Criminal Justice and Human Services, University of Cincinnati, P.O. Box 210002, 410 TC, Cincinnati, OH 45221, USA; Tel: (513) 556-0802; Fax: (513) 556-9311; E-mail: daicg@mail.uc.edu
One potential barrier to healthy eating and engaging in physical activity is residing in poverty [9]. More than one in five children (15.75 million) in the U.S. lived in poverty in 2010 [10]. Children from low-income families are at greater risk for becoming obese and developing chronic disease [11]. Children from disadvantaged family backgrounds are frequently exposed to negative influences such as: decreased educational opportunities, lack of availability of nutritious foods, inadequate exercise, and inaccessible recreational facilities. These factors may have negative influences on their physical and psychological development [12] Hence, a new vision for Healthy People 2020 is to emphasize health equity for all and afford all groups with information about healthy lifestyle habits [13].

One strategy to promote health education among children is to intervene in the school setting. Research has indicated that school-based interventions are effective in reducing the prevalence of childhood obesity [14]. School-based programs provide an opportunity for implementing health education programs to educate children on ways to eat healthy and engage in more physical activity [15]. During afterschool programs, the staff has the potential to implement programs to increase positive experiences among children who lack access to resources that promote healthy lifestyles [16]. However, research on 
the acceptability and feasibility of afterschool-based interventions to prevent obesity is still minimal [17].

This study evaluated the impact of the Children's Health Eating and Exercise Program (CHEE) developed to disseminate information from the Traffic Light Diet [18]. Three food groups are used to teach children about its health content. These include green light foods (e.g. broccoli, tomatoes, oranges, foods that are high in vitamins, fiber and minerals, and low in fat), yellow light foods (e.g. dairy foods, pasta, which should be eaten in moderation), and red light foods (e.g. cookies and fried foods that are high in calories and low in nutrients). The Traffic Light Diet has been successfully used to help children with weight loss and behavior changes by teaching about healthy food choices to obese and overweight children [19]. The Winning with Wellness (WWW) Program was implemented to promote healthy eating at a rural elementary school. The WWW Program was also adapted from the Traffic Light Diet. Findings indicated improved food choices and healthy eating, but results also suggested that finding time to implement the program during the school day could be challenging [20].

The CHEE Program was delivered to 36 urban Appalachian children and adolescents in a community setting. In addition to emphasizing eating more green light foods and fewer red light foods, the CHEE Program also emphasized the importance of daily exercise in maintaining health. The older children $(M=$ 16.21 years) participated in five groups, whereas the younger children ( $M=8$ years) participated in six groups. Sessions for the older group lasted for about 45 minutes while sessions with the younger children lasted for 90 minutes. Results indicated that participants improved in healthy eating, such as consuming more vegetables and fewer French Fries and chips (i.e. snacks). Results also indicated that children displayed knowledge of the green and red light food categories, but were less knowledgeable about yellow light foods. There was no significant change in levels of exercise at the end of the program [21]. Thus, the current study added a more intensive physical activity program, having more equipment available for children to use and more time to engage in physical activities at each session. In addition, younger participants were recruited, which extended knowledge about the program. Activities were fun and culturally appropriate, such as jump rope, tag, etc., as previous research has shown that engagement in these types of activities improved children's activity levels [22]. Thus, there were two specific aims of the program evaluation: (1) to gain an understanding of what children learned from the intervention, and (2) to assess whether eating and exercise behaviors changed in the intervention versus the comparison group.

\section{METHODS}

\section{Participants}

There were 33 ( 13 boys and 20 girls) children in the intervention group ranging from 5-10 years of age ( $M=$ 6 years, $S D=1$ years). Seventeen children in the intervention group were Caucasian, ten were African American, three were Hispanic, and three were biracial. Children self-selected to be members of intervention group. The comparison group was recruited from other afterschool programs held at the elementary school. A total of 24 (13 boys and 11 girls; $M=6$ years, $S D=1$ years, range $=5-9$ years) children were in the comparison group. Seventeen were Caucasian, six were African American, and one was biracial. This study was conducted in an elementary school where seventy-five percent of the families are at low-income or poverty levels.

\section{Description of Lessons}

The sessions were conducted twice a week in the school gymnasium. A typical session included education about: (1) healthy eating [for 20 minutes], (2) exercise [for 35 minutes], and (3) wrap-up discussion on the importance of healthy eating and exercise [for 5 minutes]. Children were recognized or awarded for their participation with a snack, such as raisins. The weekly lessons are described in Table 1.

For the healthy eating lessons, weekly sessions focused on discussing green and red light foods. Children learned about packing a healthy lunch, eating a healthy snack, cooking healthy, and consuming more fruits and vegetables. Children also learned about and healthy foods to keep in their refrigerator at home.

For the exercise lessons, group leaders involved the children in a variety of activities including soccer, basketball, relay races, jump rope, tag, kicking a shuttlecock (a traditional Asian game, with similar objectives to hacky sack), and other running games. Exercise equipment (e.g. hula hoops, foam balls, scooters, plastic bowling equipment, and Frisbees) was provided. Children were also allowed to create their own fun games, such as creating obstacle courses from materials available in the gym (cones, mats, etc.). 
Table 1: Weekly Plan: Healthy Eating Lessons and Exercise Activities

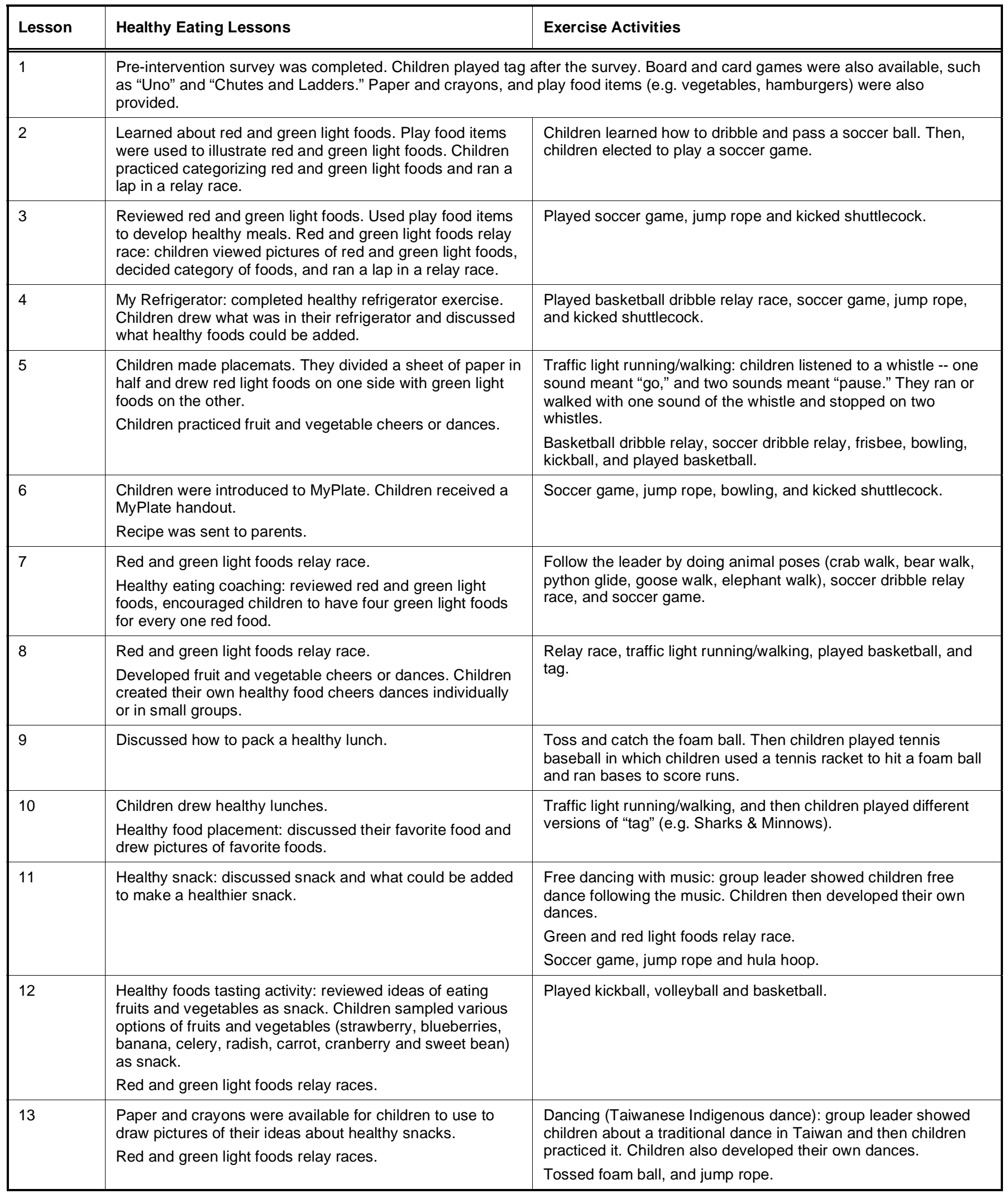


(Table 1). Continued.

\begin{tabular}{|l|l|l|}
\hline Lesson & Healthy Eating Lessons & Exercise Activities \\
\hline \hline 14 & $\begin{array}{l}\text { Paper and crayons were available for children to use to } \\
\text { draw pictures of their ideas about healthy snacks. }\end{array}$ & $\begin{array}{l}\text { SPUD (children were assigned a number, and then the group } \\
\text { leader tossed the soft ball and called a number and everyone ran } \\
\text { away. The student with the number had to catch the ball and } \\
\text { then everyone stopped moving. The student could move 4 steps } \\
\text { and threw the soft ball to the person he/she targeted.). Tag, } \\
\text { handball, jumping jacks and soccer were other activities. }\end{array}$ \\
\hline 15 & $\begin{array}{l}\text { Paper and crayons were available for children to use to } \\
\text { draw pictures of their ideas about healthy snacks. }\end{array}$ & Kickball, bowling, jump rope and toss foam ball. \\
\hline 16 & $\begin{array}{l}\text { Paper and crayons were available for children to use to } \\
\text { draw pictures about healthy eating. } \\
\text { Red and green light foods relay race. }\end{array}$ & SPUD and handball. \\
\hline 17 & $\begin{array}{l}\text { Post-intervention survey was completed. Children played tag after the survey. Board and card games were also available, such } \\
\text { as "Uno" and "Chutes and Ladders." Papers, crayons, and play foods were also provided. }\end{array}$ \\
\hline 18 & $\begin{array}{l}\text { Scooters, jump ropes, soccers and foam balls were provided. Paper and crayons were also available. Children also played red } \\
\text { and green light foods relay race and tag. }\end{array}$ \\
\hline
\end{tabular}

For parent involvement, parents received handouts, newsletters discussing the importance of healthy eating and daily exercise, and recipes for preparing healthy meals.

\section{Procedures}

Institutional Review Board (IRB) approval was obtained from one Midwestern university. Parental consent and child assent were required for children to participate. The program was implemented and evaluated by a team consisting of one faculty member from the health promotion and education program, and graduate students with a major in community health. A survey that has been utilized [21] was adapted to assess children's opinions about their eating and exercise habits before and after program participation. Questions examined participants' eating and physical activity behaviors. For example, "Yesterday, did you eat French Fries or chips?" The anchor points of the scale were: $1=$ no, $2=$ one time, $3=$ two times, $4=$ three or more times. For the questions examining the children's exercise regime, children indicated "How many of the past 7 days did you exercise that made you breathe hard for at least 20 minutes?" $(0=0$ day to $7=7$ days). The follow-up surveys consisting of the same questions were completed at the seventeenth session of the program instead of the scheduled eighteenth session due to several participants were leaving school for their winter break during the last week of the semester. Children in the intervention group also provided information about what they learned about healthy eating (e.g. what did you learn about green light foods?) and exercise (e.g. what new things did you learn about exercise?) after participating in the program. Assessors read questions for younger participants with limited reading abilities. Parents were given surveys and responded to questions (e.g., do you think your child is eating more healthy food because of being in the group?) on a three-point scale ( 1 = yes, 2 $=$ no, $3=$ don't know) to assess their impressions of the CHEE Program.

\section{Data Analysis}

All data were analyzed using IBM-SPSS, version 22.0. Quantitative data were analyzed using repeated measures ANOVAs. Repeated measures ANOVAs were used to compare pre- and post-intervention consumption of French Fries and chips, vegetables, fruits, fruit juice, sweets, soda, and pre- and postintervention physical activity participation for the intervention versus the comparison group. Data about what children learned about healthy eating and exercise, and parent responses are also presented.

\section{RESULTS}

Results of the repeated measures ANOVA for change in vegetable consumption indicated a significant difference from pretest to posttest, $F(1,44)$ $=6.056, p=.018$. Irrespective of whether they were in the intervention or comparison group, children reported consuming more vegetables at the end of the program $(M=2.30, S D=1.07)$ compared to the beginning of the program $(M=1.85, S D=1.05)$. Means and standard deviations for pre- and post-intervention change in survey questions are presented in Table 2. Repeated measures ANOVAs for other key outcome variables (i.e. consumption of chips, fruits, fruit juice, sweets, exercise, and soda) did not yield significant findings. 
Table 2: Results for Changes in Key Outcome Variables

\begin{tabular}{|c|c|c|c|c|c|c|c|c|}
\hline \multirow[t]{3}{*}{ Variables } & \multicolumn{4}{|c|}{ Pre-intervention } & \multicolumn{4}{|c|}{ Post-intervention } \\
\hline & \multicolumn{2}{|c|}{ Intervention } & \multicolumn{2}{|c|}{ Comparison } & \multicolumn{2}{|c|}{ Intervention } & \multicolumn{2}{|c|}{ Comparison } \\
\hline & $M$ & $S D$ & $M$ & $S D$ & $M$ & $S D$ & $M$ & $S D$ \\
\hline French Fries/chips & 1.59 & .91 & 1.78 & 1.00 & 1.69 & 1.00 & 2.06 & 1.21 \\
\hline Vegetables & 2.00 & 1.17 & 1.59 & .795 & 2.41 & 1.15 & 2.12 & .93 \\
\hline Fruits & 2.34 & 1.26 & 2.17 & .99 & 2.59 & 1.18 & 2.39 & 1.09 \\
\hline Fruit Juice & 2.24 & 1.15 & 1.50 & .71 & 2.28 & 1.22 & 2.00 & 1.14 \\
\hline Sweets & 2.22 & 1.28 & 2.00 & 1.19 & 2.11 & 1.16 & 1.67 & 1.19 \\
\hline Soda & 2.34 & 1.23 & 2.00 & 1.19 & 1.76 & 1.15 & 2.06 & 1.16 \\
\hline Exercise & 1.18 & .39 & 1.22 & .43 & 1.36 & .49 & 1.39 & .50 \\
\hline Days of Exercise & 3.66 & 3.27 & 3.83 & 2.53 & 4.59 & 2.89 & 3.89 & 2.68 \\
\hline
\end{tabular}

At the posttest, children $(n=29)$ responded to questions addressing what they learned about red light and green light foods. Twenty-eight children (97\%) correctly discussed what red light foods were, and twenty-six children (90\%) were able to describe what green light foods were. Children's answers about red light foods included comments such as, red light foods are not healthy, are foods that are sweetened and fat, are "No No" foods, and are foods we should stop eating or eat less frequently. The majority of children indicated that green light foods are healthy, are vegetables and fruits, are "Yes Yes" foods and we should eat more of them. One child did not correctly identify red and green foods.

Table 3 presents the details about what children said they learned about exercise.

Table 3: Results of Participants' Answers about Exercises They Learned

\begin{tabular}{|c|c|c|}
\hline & Number of Children & Percent \\
\hline \hline $\begin{array}{c}\text { Keeps you } \\
\text { strong/healthy/live longer }\end{array}$ & 5 & $20 \%$ \\
\hline Yoga & 5 & $20 \%$ \\
\hline Push-up & 4 & $16 \%$ \\
\hline New game & 4 & $16 \%$ \\
\hline Exercise everyday & 2 & $8 \%$ \\
\hline Nothing & 2 & $8 \%$ \\
\hline Sit-up & 1 & $4 \%$ \\
\hline Fun & 1 & $4 \%$ \\
\hline Don't know & 1 & $4 \%$ \\
\hline
\end{tabular}

Surveys were sent to parents of children in the intervention group. Six parent surveys were collected.
Five parents said that prior to the program they had talked to their child about healthy eating and exercise. Five parents mentioned that their child had talked to them about having healthy eating and exercise goals prior to beginning the program. All of the parents reported that their child talked about red and green light foods and healthy eating, and were eating more healthy foods at home because of participating in the program. Five of six parents $(83 \%)$ stated that their child was exercising more because of participating in the program. All of the parents reported that they received the recipes; however, only two parents replied that they had used the recipes (i.e. a burger meal, taco meal, veggie meal, and peanut butter cookies).

\section{DISCUSSION}

Findings indicated that children in the intervention group were learning about red and green light foods. These findings are consistent with other studies indicating the acceptability and feasibility of the adapted Traffic Light Diet for children [21, 22]. Children in the intervention and comparison groups were eating more vegetables at the post-intervention assessment. This may have occurred because children were talking to each other about the program or learning about healthy eating in other school programs. Parents reported that their children were eating more healthy foods at home and exercising more frequently because of participating in the group.

Children in the comparison group could have learned about the intervention, obscuring differences between groups. Therefore, we conducted a post hoc analysis of pre- and post-intervention changes for the intervention group. Results indicated that they ate more vegetables and drank less soda with sugar when 
assessed at the posttest than at pretest (see Table $\mathbf{4}$ for $t$ values and see Table 3 for Means and Standard Deviations for the intervention group).

Table 4: Post Hoc Analysis - Paired t-Tests for Intervention Group

\begin{tabular}{|c|c|c|}
\hline Variable & $\boldsymbol{t}$ & $\boldsymbol{p}$ \\
\hline \hline French Fries/chips & -.451 & .655 \\
\hline Fruits & -.925 & .363 \\
\hline Vegetables $^{*}$ & -3.36 & .002 \\
\hline Fruit Juice & -.128 & .899 \\
\hline Sweets & .350 & .729 \\
\hline Exercise & -1.724 & .096 \\
\hline Days of Exercise & -1.448 & .159 \\
\hline Soda* & 2.174 & .038 \\
\hline
\end{tabular}

Note. *denotes significant difference between mean scores. See Table $\mathbf{3}$ for means and standard deviations for healthy eating and exercise questions preand post-intervention for the intervention group.

Several lessons were learned from conducting the program. For example, the program leader observed that younger children (5 to 6 years old) and older children (7 to 9 years old) had different levels of skills for engaging in physical activities. Moreover, there were gender differences in the involvement in the physical activity that may have impacted results. Many of the boys tended to become involved in competitive games, while girls preferred different types of activities such as jump rope and dance. Future interventions should separate children into different groups based on their age, gender, or interests, and play stations could be used to provide different options for children. Results of the study demonstrated that children's knowledge about healthy eating and the importance of regular exercise was improved, but their engagement several types of in healthy eating and exercise behaviors did not change. Hence, it is crucial for health educators to intervene to help fill the gap between cognitive and behavior change by motivating children and families to engage in more health behaviors [23]. Eating and exercise diaries could be used to document what children consume as well as what and how much physical activity they are involved in at home.

Several factors limited the generalizability of the findings of the study. First, the sample size was small, and the comparison group was selected based on convenience. Future studies should use a comparison group with matched child age or ethnic group. Using physiological measures of exercise, observations of mealtimes, and food or exercise diaries would have provided more objective information about whether behaviors changed. Second, other strategies could be applied to increase response rate for parent surveys, such as providing a gift card for completion of the survey. Also, future research on parents' eating and physical activity behaviors as well as holding lessons to teach parents about the CHEE Program is crucial for children's learning about and the implementation of healthy lifestyles at home.

Results of the study indicated that children and parents were satisfied with the intervention and dissemination of knowledge about the Traffic Light Diet was occurring. Involving parents or other family members in the program may result in positive impacts on children's eating and exercise behaviors [24]. Childhood obesity is growing at an alarming rate [1], more health and exercise programming is needed in the regular school curriculum. Moreover, it will be important to continue examining the feasibility of obesity prevention programs in community settings, such as afterschool programs, to improve children's knowledge of healthy eating and engagement in physical activity.

\section{REFERENCES}

[1] Ogden CL, Carroll MD, Kit BK, Flegal KM. Prevalence of childhood and adult obesity in the United States, 2011-2012. JAMA 2014; 311: 806-14 http://dx.doi.org/10.1001/jama.2014.732

[2] World Health Organization. Childhood overweight and obesity. [cited 2014 Oct 20]: Available from: http://www.who. int/dietphysicalactivity/childhood/en/index.html

[3] Zhao LY. Overweight and obese issues among children and teenagers in Taiwan. Zhong Hua Ti Yu 2008; 22: 35-46.

[4] Puhl RM, Latner JD. Stigma, obesity, and the health of the nation's children. Psychol Bull 2007; 133: 557-80. http://dx.doi.org/10.1037/0033-2909.133.4.557

[5] World Health Organization. Population-based approaches to childhood obesity prevention. Geneva: World Health Organization 2012

[6] Fowler-Brown A, Kahwati LC. Prevention and treatment of overweight in children and adolescents. Am Fam Physician 2004; 69: 2591-8.

[7] Sharma M, Wagner DI, Wilkerson J. Predicting childhood obesity prevention behaviors using social cognitive theory. Int Q Community Health Educ 2006; 24: 190-202.

[8] Sothern MS. Obesity prevention in children: Physical activity and nutrition. Nutrition 2004; 20 : 704-8. http://dx.doi.org/10.1016/j.nut.2004.04.007

[9] Edwards MB, Miller JL, Blackburn L. Afterschool programs for health promotion in rural communities: Ashe County Middle School 4-H Afterschool Program. J Public Health Manag Pract 2007; 17: 283-7. http://dx.doi.org/10.1097/PHH.0b013e318207ce3a

[10] Macartney S. Child poverty in the United States 2009 and 2010: Selected race groups and Hispanic origin. American Community Survey Briefs, United States Census Burea 2011. 
[11] Centers for Disease Control and Prevention. Trends in the prevalence of extreme obesity among US preschool-aged children living in low-income families, 1998-2010. JAMA 2010; 308: 2563-5.

[12] Pampel FC, Krueger PM, Denney JT. Socioeconomic disparities in health behaviors. Annu Rev Sociol 2011; 36: 349-70.

http://dx.doi.org/10.1146/annurev.soc.012809.102529

[13] Department of Health and Human Services. Disparity. [cited 2014 Oct 20]; Available from: http://www.healthypeople.gov/ 2020/about/DisparitiesAbout.aspx

[14] Gonzalez-Suarez C, Worley A, Grimmer-Somers K, Dones V. School-based Interventions on childhood obesity: A metaanalysis. Am J Prev Med 2009; 37: 418-27. http://dx.doi.org/10.1016/i.amepre.2009.07.012

[15] Beets M, Beighle A, Erwin H, Huberty JL. Impact of afterschool programs to increase physical activity and fitness - A meta-analysis. Am J Prev Med 2009; 36: 527-37. http://dx.doi.org/10.1016/j.amepre.2009.01.033

[16] Afterschool Association. Afterschool fosters success in school. [cited 2014 Oct 20]; Available from: http://www. afterschoolalliance.org/issue_31_sch_success.cfm

[17] Perterson KE, Fox MK. Addressing the epidemic of childhood obesity through school-based interventions: What has been done and where do we go from here? J Law Med Ethics 2007; 35: 113-30.

http://dx.doi.org/10.1111/j.1748-720X.2007.00116.x
[18] Epstein LH. The Traffic Light childhood weight control program: Traffic Light: Kids program. University of Buffalo: Author 2005.

[19] Epstein LH, Gordy CC, Raynor HA, Beddome M, Kilanowski $\mathrm{K}$, Paluch $\mathrm{R}$. Increasing fruit and vegetable intake and decreasing fat and sugar intake in families at risk for childhood obesity. Obes Res 2012; 9: 171-8. http://dx.doi.org/10.1038/oby.2001.18

[20] Schetzina KE, Dalton WT, Lowe EF, et al. A coordinated school health approach to obesity prevention among Appalachian youth: The Winning with Wellness Pilot Project. Fam Community Health 2009; 32: 271-85. http://dx.doi.org/10.1097/FCH.0b013e3181ab3c57

[21] Nabors L, Burbage $\mathrm{M}$, Pangallo $\mathrm{J}$, et al. Delivery and evaluation of a pilot obesity prevention project for urban Appalachian children. O J Ped 2013; 3: 300-5. http://dx.doi.org/10.4236/ojped.2013.34054

[22] Story $M$, Sherwood NE, Himes JH, et al. An afterschool obesity prevention program for African-American girls: The Minnesota GEMS pilot study. Ethn Dis 2003; 13: 54-64.

[23] Bandura A. Health promotion by social cognitive means. Health Educ Behav 2004; 31: 143-64.

http://dx.doi.org/10.1177/1090198104263660

[24] Summerbell CD, Waters E, Edmunds LD, Kelly S, Brown T, Campbell KJ. Interventions for preventing obesity in children. Cochrane Database Syst Rev 2011; 12: 1-223. 